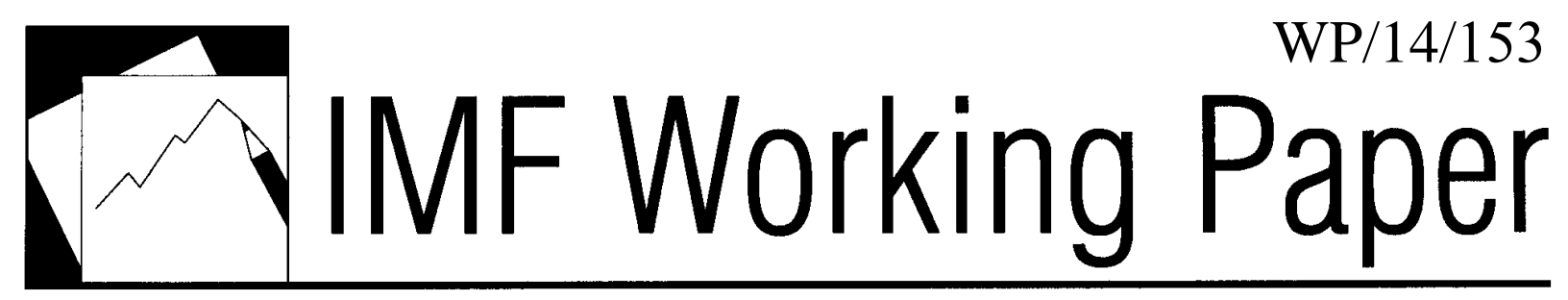

\title{
Unemployment and Structural Unemployment in the Baltics
}

Christian Ebeke and Greetje Everaert 


\title{
IMF Working Paper
}

European Department

\section{Unemployment and Structural Unemployment in the Baltics ${ }^{1}$ \\ Prepared by Christian Ebeke and Greetje Everaert}

Authorized for distribution by Daria Zakharova

August 2014

\section{This Working Paper should not be reported as representing the views of the IMF. The views expressed in this Working Paper are those of the author(s) and do not necessarily represent those of the IMF or IMF policy. Working Papers describe research in progress by the author(s) and are published to elicit comments and to further debate.}

\begin{abstract}
While the unemployment rate in the Baltics has fallen sharply from its crisis-peaks, it remains close to double digits. This paper estimates the structural component of the jobless rate in the three Baltic countries and analyzes its causes. Our main findings are that the current still elevated levels of unemployment mostly reflect structural factors. We then turn to why structural unemployment is so high. This paper points to skill mismatches, high tax wedges, and unemployment and inactivity traps as potential causes.
\end{abstract}

JEL Classification Numbers: J63, J64, J68

Keywords: Unemployment, Structural Unemployment, Baltics, Estonia, Latvia, Lithuania Author's E-Mail Address: Cebeke@,imf.org and Geveraert@imf.org

\footnotetext{
${ }^{1}$ We thank Daria Zakharova, Julie Kozack, Tom Dorsey, Mahmood Pradhan, Martin Lindpere, Petya Koeva Brooks, participants at the Baltic Cluster meeting in Riga on March 4, 2014, and IMF colleagues from various Departments. Comments from authorities at the National Bank of Estonia, Latvia, and Lithuania, and at the Ministries of Finance of Estonia, Latvia, and Lithuania are also gratefully acknowledged. Excellent research assistance from Bartek Augustyniak is gratefully acknowledged. We would also like to acknowledge Eduardo Castro, Betrand Gruss, Giang Ho, and Mark Lutz for their involvement in the early phase of this research project.
} 
Abstract....... 1

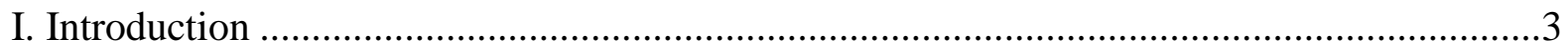

II. What is the Structural Level of Unemployment?........................................................4

A. Estimating the Structural Component of the Unemployment Rate..........................4

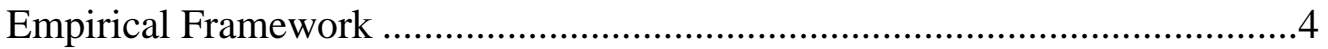

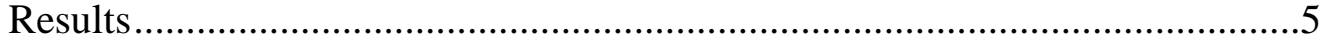

B. Is Structural Unemployment Really That High? Robustness Checks ......................7

Historical Experience, Real Wage Behavior, and Other Independent

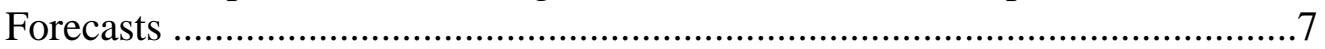

Evidence from the Beveridge Curve ...........................................................8

Evidence from the Okun Relationship ................................................11

III. What Explains the High Level of Structural Unemployment in the Baltics? ...................14

A. Traditional Factors_-Labor Market Characteristics ...........................................14

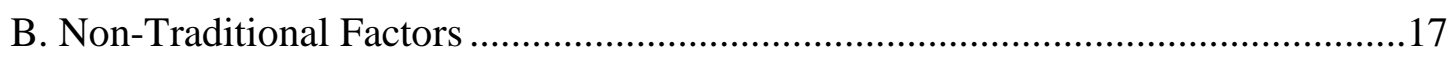

Are Skill Mismatches a Factor? ..............................................................17

What Role Does Migration Play? ............................................................21

IV. Conclusions and Policy Recommendations ..........................................................22

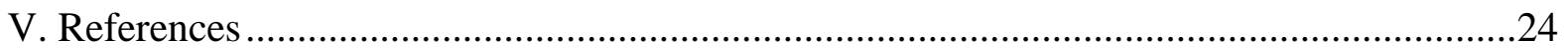




\section{INTRODUCTION}

Unemployment remains persistently high in the Baltic countries. While it has fallen significantly from its post-crisis peak, it remains in the $8-12$ percent range. And it is particularly high for youth, and about half the unemployed have been out of a job for more than one year.

The aim of this paper is to examine the reasons behind the persistently high level of unemployment rate in the

Baltics. Finding a solution to unemployment depends critically on whether it reflects cyclical or structural factors. Policies to address cyclical

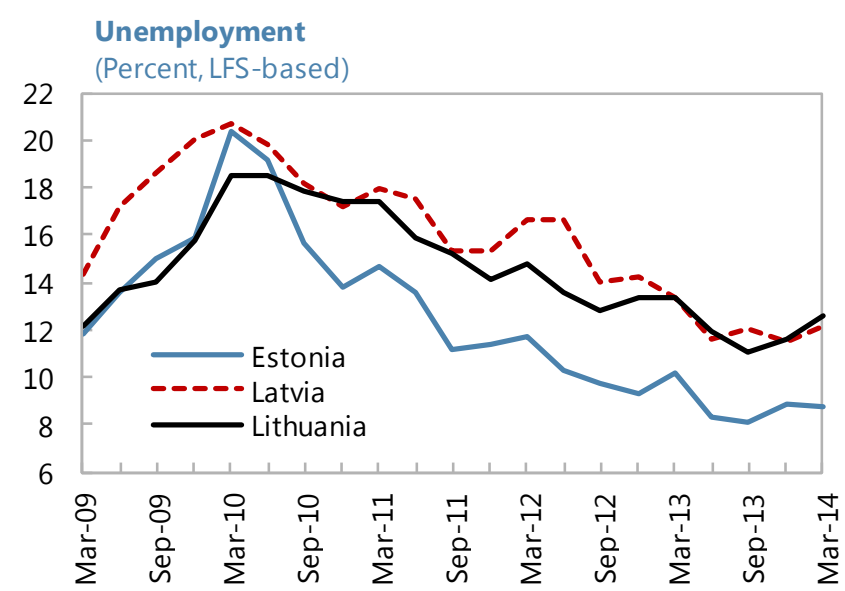

Source: European commission. unemployment primarily focus on demand management. However, addressing structural unemployment tends to require deep and targeted reforms that tackle the underlying forces of why the unemployed do not find the way to matching jobs.

Hence, we first analyze whether still high unemployment reflects cyclical or structural factors (Section II). We do so by drawing on the recent empirical literature that uses augmented Phillips curves and state-space representations to estimate the Non-Accelerating Inflation Rate of Unemployment (NAIRU). We find that that the current level of unemployment is close to, or in the case of Estonia somewhat below, the structural level, implying that it will be more difficult to reduce unemployment going forward, at least not without engendering wage pressures in the future. We provide a number of robustness checks for our findings as well.

We then examine the possible causes of the high level of structural unemployment in Section III. We find that, unlike in many other economies, high structural unemployment appears to coexist with relatively flexible labor markets, suggesting that the main culprit is not a lack of dynamism in the labor market. At the same time, taxes on labor are high, which raises the cost of hiring, particularly lower skilled workers. Skill mismatches also appear to be a concern, and policies to address them are underused. Conclusions and policy recommendations are summarized in Section IV. 


\section{What IS THE STRUCTURAL LEVEL OF UNEMPLOYMENT?}

\section{A. Estimating the Structural Component of the Unemployment Rate}

\section{Empirical Framework}

To estimate the level of structural unemployment in the Baltics, we draw on a number of recent empirical approaches aimed at isolating a time-varying NAIRU. In particular, we draw on the approaches used by Laubach (2001), the OECD (discussed in Gianella et al., 2008 and, in Guichard and Rusticelli, 2011) and the IMF (2013). The analysis consists of estimating time-varying NAIRUs contained in a reduced form Phillips curve equation (linking inflation to the unemployment gap) by means of the Kalman filter. One of the main advantages of this method is that an explicit econometric estimation, unlike a filter, helps assess the uncertainty as reflected in confidence intervals, and helps avoid the end point problem common to simple statistical filters such as the HP filter. In particular, applying simple filters (such as the HP) increases the risk of putting too much weight on the end data points. The Phillips curve equation controls for short-term (supply) shocks captured by import price inflation. Domestic inflation is measured by core consumer price inflation. The estimated Phillips curve relationship takes the following form:

$$
\pi_{t}=\theta_{t} \bar{\pi}_{t}-\kappa_{t}\left(U_{t}-U_{t}^{*}\right)+\gamma_{t} \pi_{t}^{m}+\epsilon_{t}
$$

where $\pi_{t}$ is the year-on-year core CPI inflation adjusted for changes in indirect taxes, $\bar{\pi}_{t}$ are inflation expectations approximated by the past 4-quarter rolling average of the core CPI inflation, $\theta_{t}$ is a time-varying parameter, $U_{t}$ is the unemployment rate, $U_{t}^{*}$ is the NAIRU, $\pi_{t}^{m}$ is import price inflation, and $\epsilon_{t}$ is a cost-push shock. Depending on data availability, the sample period starts in the early 2000s and ends in Q4 2013.

One of the main innovation of this framework is that it allows specifying the dynamics of both the NAIRU and the unemployment gap. The unemployment gap and the NAIRU are assumed to follow an AR(1) and random walk processes, respectively. This adjustment has the advantage that the NAIRU is inferred not only on the basis of inflationary pressures, but also on the basis of the unemployment rate dynamics captured by the AR(1) process. Assumptions on the stochastic process followed by the NAIRU follow Laubach (2001) and Gianella et al. (2008) and, rely on two transition equations specifying the time-series properties of respectively the NAIRU and the unemployment gap (the gap between the NAIRU and the unemployment rate). First the NAIRU is modeled as a simple random walk process, its transition equation takes the following form:

$$
U_{t}^{*}=U_{t-1}^{*}+\epsilon_{t}^{U^{*}}
$$

where the error term $\epsilon_{t}^{U^{*}}$ is assumed to be normally distributed and uncorrelated with the error term of the Phillips curve equation $\epsilon_{t}$. Second, a law of motion is imposed on the unemployment gap to ensure that the unemployment rate converges to its structural rate in 
the absence of shocks and, the unemployment gap is assumed to follow an autoregressive process:

$$
\left(U_{t}-U_{t}^{*}\right)=\rho\left(U_{t-1}-U_{t-1}^{*}\right)+\epsilon_{t}^{\left(U-U^{*}\right)}
$$

The estimations of a state-space representation requires some additional assumptions. For example, the values and variances of the two state variables (the NAIRU and the unemployment gap) in the initial period have to be pre-specified. The goal is to strike a balance between avoiding estimating a NAIRU which tracks too closely the actual dynamics of the jobless rate and seeking a NAIRU which exhibits some reasonable variability. The initial value of the NAIRU has been set equal to the unemployment rate in each country seen in the mid of the 2000s (2005Q1), given that the Baltic economies were assessed to have broadly closed output gaps at that time. The initial value of the unemployment gap is set equal to the difference between the unemployment rate in the initial period of the sample and the specified initial NAIRU. Second, assumptions are made about the relative variances of the residuals of the three equations. The variance of the error term in the transition equation of the NAIRU (equation [1.2]) relative to the one of the error term in the Phillips curve equation (equation [1.1]) determines the smoothness of the NAIRU series. The smaller this 'signal-to-noise ratio', the less volatile will be the resulting NAIRU. Therefore, we allow for signal-to-noise ratios in the range of estimates in the literature (see Laubach, 2001) and consistent with a certain variability of the estimated NAIRUs. The estimates of the NAIRUs are robust to reasonable modifications of the signal-to-noise ratio and different assumptions regarding the initial NAIRUs and unemployment gaps. The parameters and shock variances are estimated with maximum likelihood using a nonlinear Kalman filter.

\section{Results}

Our estimates suggest that the NAIRU in the Baltics is high, relatively stable, and close to the current level of unemployment (Figure 1). ${ }^{2}$ For Lithuania and Latvia, the timevarying point estimate ranges between $103 / 4$ and 13\%/4 percent, while for Estonia it ranges between $10^{3} / 4$ and 151/4 percent. The 95-percent confidence intervals around these point estimates shrink over time — by the end of the estimation period they are $+/-1 / 4$ percentage point (1 $1 / 2$ percentage point for Lithuania). Current levels of unemployment are close to the estimated NAIRU (in 2013) for Latvia and Lithuania and somewhat below the NAIRU (in 2013) for Estonia. In other words, the still high unemployment in the Baltics appears to reflect equilibrium trends. It also implies that with output growing at potential, unemployment would not drop significantly without rising wage and inflationary pressures.

\footnotetext{
${ }^{2}$ The equilibrium or structural level of unemployment (NAIRU or NAWRU) is the level of unemployment that is consistent with a balanced economy where the output gap is closed. In this state, the level of unemployment does not generate accelerating inflationary or wage pressures. Cyclical unemployment occurs when the output gap is negative.
} 
Figure 1. Baltic Countries: NAIRU Estimates

(Percent of total labor force)
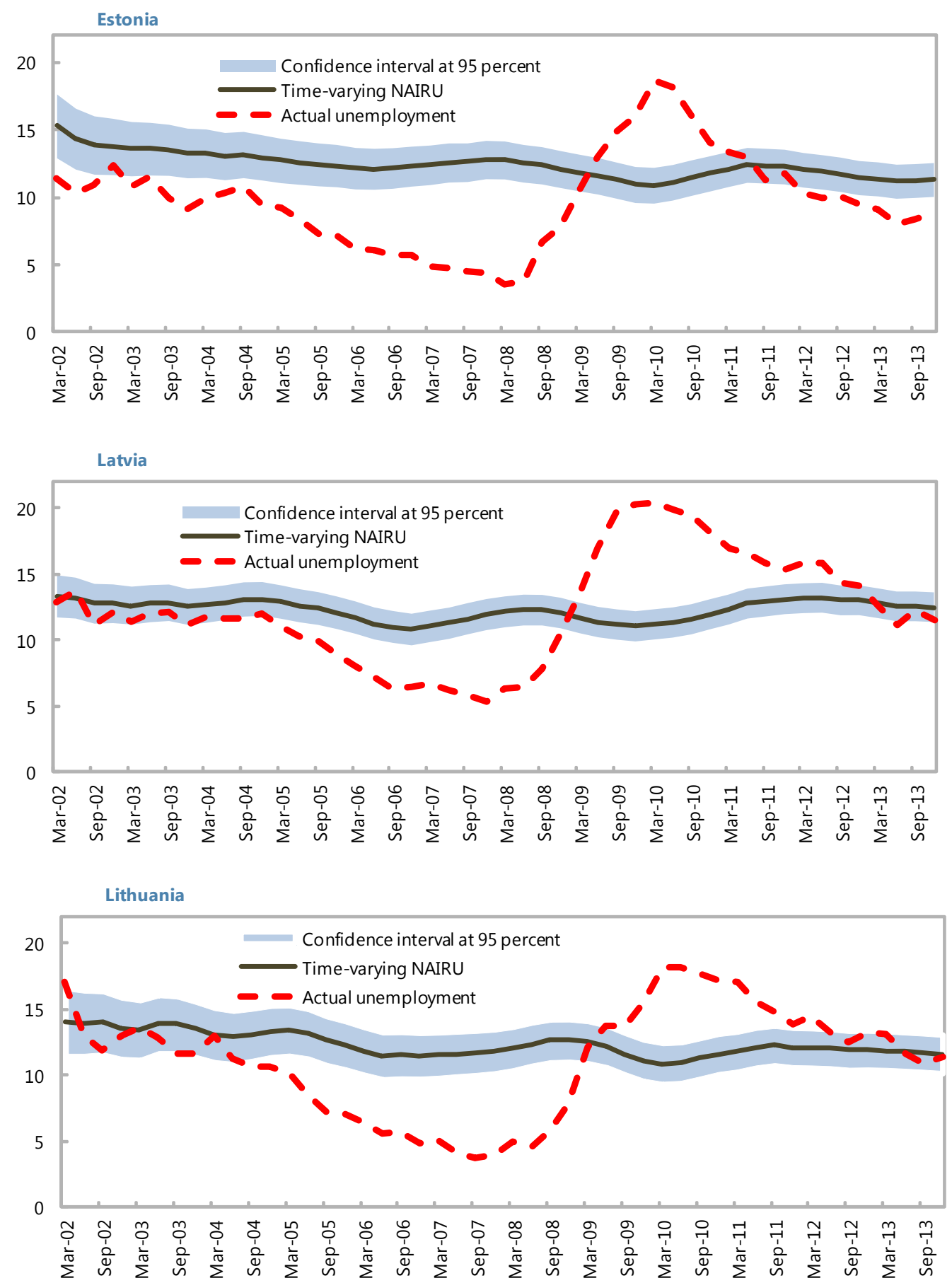

Source: National Authorities; and staff estimates. 


\section{B. Is Structural Unemployment Really That High? Robustness Checks}

In order to test the robustness of our results, we perform a number of checks. We first compare whether our results are in line with historical experience of unemployment, whether they align with real wage behavior around these NAIRU estimates, and how our estimates compare with other estimates of the NAIRU for the Baltics in the literature. Then, we test more formally whether the relationship between vacancies and unemployment (the Beveridge curve) and the relationship between output and unemployment (the Okun's law) has changed. Our robustness checks indicate that the NAIRU is indeed high and relatively stable over time.

\section{Historical Experience, Real Wage Behavior, and Other Independent Forecasts}

First, our estimates for the NAIRU are not out of line with historical experience of unemployment in the Baltics. In particular, while unemployment increased significantly following the crisis, a longer-time view indicates that this increase was from a historical low.
Table. Historical Average and NAIRU Unemployment

(Percent)

\begin{tabular}{lrr}
\hline & Historical Average 1/ & NAIRU average 2/ \\
\cline { 2 - 3 } Estonia & 9.7 & 12.4 \\
Latvia & 12.2 & 12.3 \\
Lithuania & 11.1 & 12.4 \\
\hline
\end{tabular}

1/ Historical average Estonia: 1993Q1-2013Q3; Latvia: 1996Q1-2013Q3; Lithuania: 1998Q2-2013Q3. 2/ 2002Q1-2013Q4.

Sources: National authorities; and IMF staff estimates

Second, real wage behavior around our NAIRU estimates is consistent with the notion that real wage growth should accelerate once unemployment falls below the NAIRU. We find that real wage growth is highly correlated with the inverse of such a calculated unemployment gap. ${ }^{3}$ This further confirms our NAIRU estimates (which were derived from inflation rather than wage dynamics). ${ }^{4}$ Also of note is the high downward flexibility of wages in the Baltics, consistent with their relatively flexible labor market institutions (see section III).

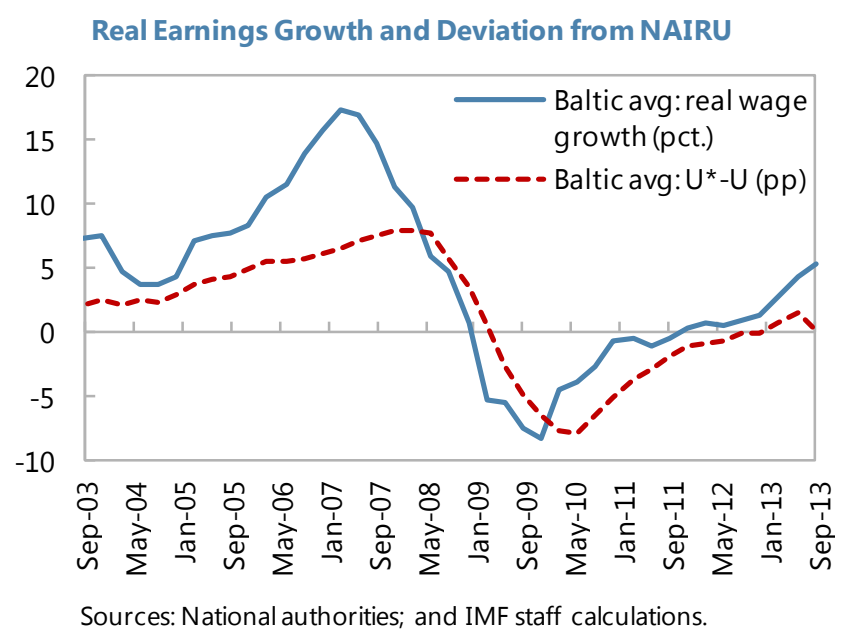

\footnotetext{
${ }^{3}$ The correlation is 0.86 percent for the Baltics. For countries individually, the correlation is 0.81 for Estonia, 0.82 for Latvia and 0.87 for Lithuania (2002q1-2013q2).

${ }^{4}$ Given that our estimation of the NAIRU relied on inflation dynamics in the Philips curve, it also indicates that a very similar result would be obtained if we were to use wage dynamics instead (the non-accelerating wage rate of unemployment or NAWRU).
} 
Third, the NAIRU estimates align with those from other international institutions. We compare our time-varying estimates to those obtained by the European Commission and the OECD. We find that, on average, our point estimates of the NAIRU are very similar.

Table. Average of Structural Unemployment Rate Estimates (2002-2013)

\begin{tabular}{lccc}
\hline & EC AMECO database & OECD estimates & IMF staff estimates \\
\hline Estonia 1/ & 11.6 & 9.8 & 12.4 \\
Latvia & 12.1 & $\ldots$ & 12.3 \\
Lithuania & 11.3 & $\ldots$ & 12.4 \\
\hline
\end{tabular}

1/ Estonia averages are 2008-13 for EU AMECO database.

Sources: European Commission; OECD; and IMF staff estimates.

\section{Evidence from the Beveridge Curve}

Next, we test whether coordinates in the Beveridge curve (the relationship between the number of job vacancies and the level of unemployment) have exhibited movements that can point to cyclical or structural shifts since the crisis (Figure 2). Tracking this relationship over time provides an indication of whether falling unemployment coincides with a higher number of vacancies (movements along the Beveridge curve), or whether falling unemployment coexists with an unchanged level of vacancies (shifts of the Beveridge curve). Movements along the curve tend to reflect cyclical variations in unemployment around an unchanged structural level. In other words, they are associated with the state of the business cycle. When labor demand is weak, employers are reluctant to hire and the number of unfilled vacancies is low while the unemployment rate is high. Shifts of the Beveridge curve on the other hand are typically associated with increased inefficiencies of labor matching and hence, increasing structural unemployment. In other words, shifts of the curve are instead of a structural nature, and linked to the efficiency of workers-to-jobs matching, or the rate at which existing jobs, are destroyed. Testing whether the Beveridge relationship has shifted provides key information to assess whether joblessness is mostly linked to temporary demand shifts or more structural changes in the efficiency of the matching process of the labor market. A first visual test of the Beveridge curve suggests that in Latvia and Lithuania it has not shifted (while in the case of Estonia, there appears a slight outward shift) over time (Figure 2), but in what follows, we also test econometrically whether there has been a shift or a change in the slope of the curve. 
Figure 2. Baltic Countries: Beveridge Curves, 2007-13

(Percent)
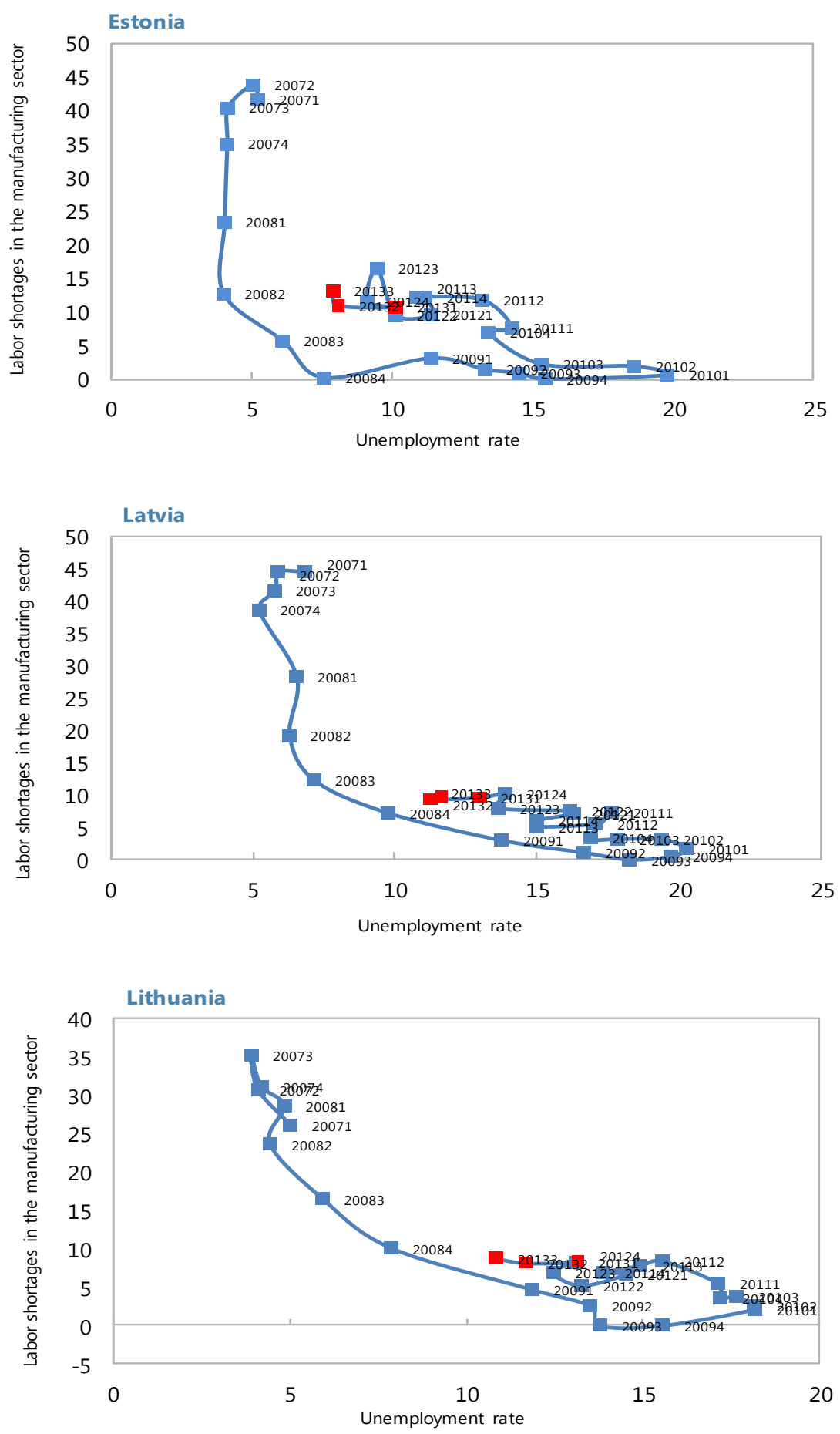

Sources: Eurostat Business Sentiment Survey; and IMF staff calculations. 
We estimate country-specific Beveridge curves for the Baltics using the new data on labor shortage in the manufacturing sector compiled by the European Commission. We follow the recent contribution by Bonthuis et al, (2013) applied to euro area countries. Since official data on job vacancy developments suffer from differences in national definitions and lack of availability over longer horizons, we consider the longer and quarterly available European Commission series of employers' perceptions of labor shortages in manufacturing as an alternative that does not suffer from such definition differences.

We model whether the Beveridge curve in the Baltics has shifted since the onset of the crisis. The framework consists of estimating country-specific Beveridge curves, but also a unique Beveridge curve for the Baltic countries as a group using a panel data specification controlling for country-fixed effects. We specify a Beveridge curve equation by regressing the unemployment rate on labor shortages (used as a proxy for vacancy rate developments), plus a range of shift parameters, following recent studies (Bonthuis et al., 2013). The model estimated for each country is represented as follows:

$$
U_{t}=\alpha+\rho U_{t-1}+\theta_{1} L S_{t}+\theta_{2} L S_{t}^{2}+\theta_{3} D_{t}^{c}+\theta_{4}\left(L S_{t} * D_{t}^{c}\right)+\epsilon_{t}
$$

where $U$ and $L S$ denote the LFS unemployment rate and the labor shortage in the manufacturing, respectively. $D_{t}^{c}$ represents the crisis dummy taking the value 1 since 2009Q1 onwards and, 0 otherwise. The quadratic term $L S^{2}$ is designed to ensure the convexity of the Beveridge curve and thus captures nonlinearities in the Beveridge relationship. To test for the impact of the crisis on the Beveridge curve, we incorporate the dummy variable $D_{t}^{c}$. Changes in the slope of the Beveridge curve due to the crisis are identified by the parameter $\theta_{4}$, while shifts in the Beveridge curve (our proxy for the effect of structural factors) are identified by the parameter $\theta_{3}$. This parameter measures to what extent, for a given level of labor shortages, the unemployment rate is "abnormally" different since the crisis compared to what would have been observed before the crisis for a given level of job vacancies. Positive or negative (and statistically significant) values of this parameter would suggest outward or inward shifts of the Beveridge curve, an indication of the emergence of structural factors (matching (in)efficiencies) at play since the crisis.

The cross-country panel data version of the equation [2.1] is specified as follows:

$$
U_{i t}=\alpha+\rho U_{i t-1}+\theta_{5} L S_{i t}+\theta_{6} L S_{i t}^{2}+\theta_{7} D_{t}^{c}+\theta_{8}\left(L S_{i t} * D_{t}^{c}\right)+u_{i}+\epsilon_{i t}
$$

where country-fixed effects are controlled for through $u_{\mathrm{i}}$. Because equation [2.2] includes both the lagged dependent variable and country-fixed effects, OLS estimates are likely to be biased because of the correlation between $U_{\mathrm{it}-1}$ and $u_{\mathrm{i}}$. We correct for this bias using the Least Square Dummy Variable Corrected estimator (LSDVCE) which is suitable in the presence of a dynamic panel model with large $T$ and small $N$.

Econometric estimates do not reject the hypothesis that Beveridge curves have not shifted since the crisis. In other words, the Beverdige curve has remained stable over time. This result is consistent with the finding that structural unemployment has been broadly 
stable without a noticeable and significant structural break due to the crisis. The models are estimated with quarterly data spanning from 2000Q1 through 2013Q3. Regardless of the specification (time-series or cross-country panel approaches), we did not find any statistically significant estimate of the parameters $\theta_{3}$ and $\theta_{7}$. We also did not find that the slopes of the Beveridge curves have changed since the crisis. Movements of job vacancies and the unemployment rate since the crisis were therefore consistent with short-term cyclical shocks in the labor market while structural unemployment has remained elevated but broadly stable. These results contrast with the findings of Bonthuis et al. (2013) who find that Beveridge curve slopes remained unchanged since the crisis in the Euro area, however, outward shifts in the curve were significant (except in Germany where an inward shift was found).

Table. Beveridge Curve Estimates for the Baltic Countries

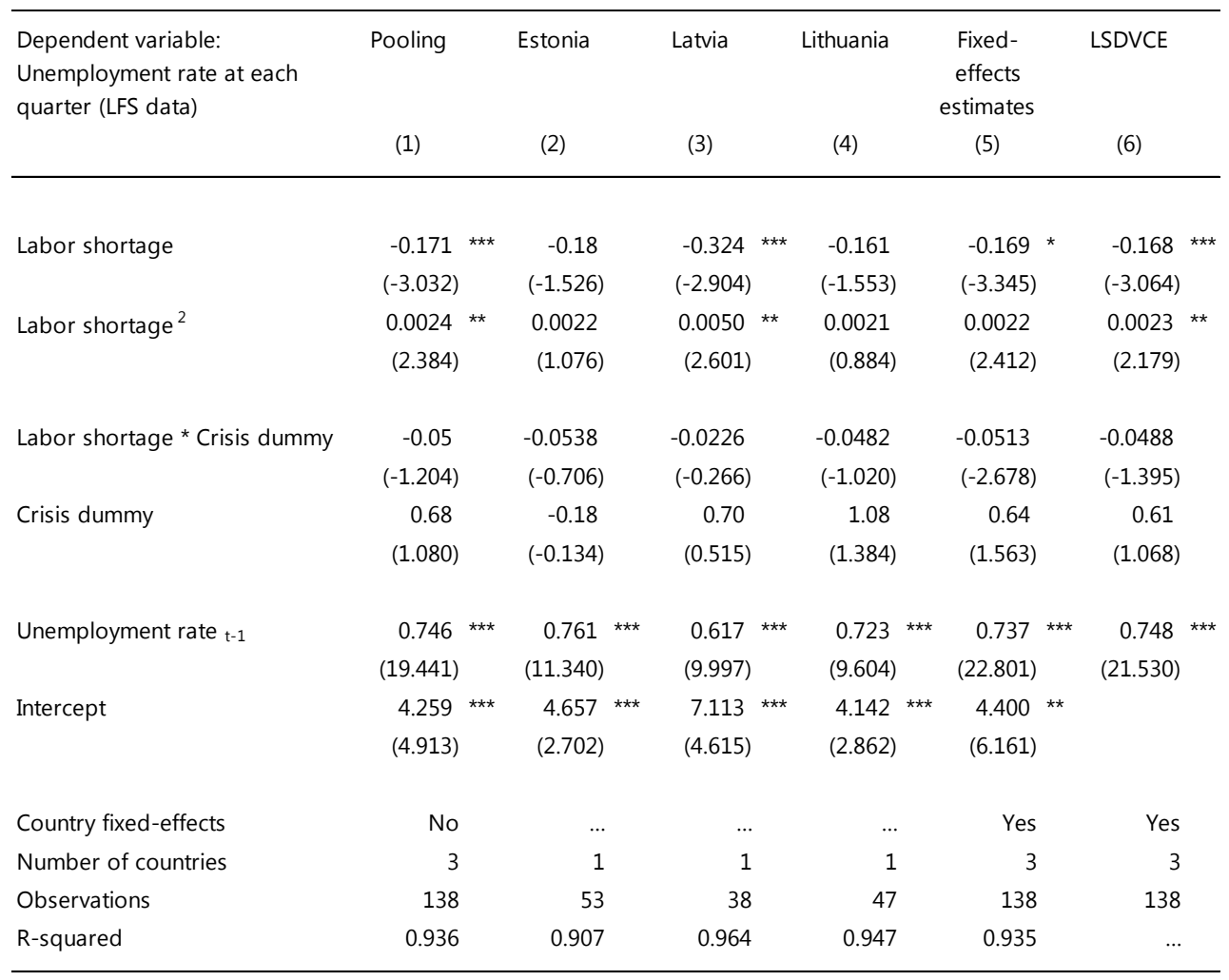

Robust $T$-statistics in parentheses.

${ }^{* * *} p<0.01,{ }^{* *} p<0.05$, and ${ }^{*} p<0.1$.

\section{Evidence from the Okun Relationship}

\section{Finally, we test whether the Okun relationship, which relates changes in the} unemployment rate to output dynamics, has remained stable. The Okun relationship predicts how much unemployment is expected to change in response to a given change in output. The literature uses specifications in both levels and in differences, with the specification in levels taking the following form:

$$
U_{t}-U^{*}=\beta\left(Y_{t}-Y^{*}\right)+\varepsilon_{t}
$$


where $U_{t}$ and $Y_{t}$ denote the level of unemployment and the log of output at time $\mathrm{t}$ respectively, $U^{*}$ and $Y^{*}$ are the level of structural unemployment and the log of potential output respectively, and $\varepsilon_{\mathrm{t}}$ is the error term assumed to be normally distributed. The specification in differences is obtained by substituting $\mathrm{U}^{*}$ and $\mathrm{Y}^{*}$ with $\mathrm{U}_{\mathrm{t}-\mathrm{i}}$ and $\mathrm{Y}_{\mathrm{t}-\mathrm{i}}$ respectively. $\beta$ is referred to as "Okun's beta", as it describes the relationship between output and unemployment.

Recent studies suggest that the Okun relationship tends to be stable over time in most countries. Ball et al. (2013) confirms this, and finds that, while temporary deviations from Okun's law occur, these are usually short-lived and modest in size. But Okun's betas do vary across countries, likely reflecting idiosyncratic features in national labor markets. For instance, Okun's beta for the United States is estimated at between -0.4 to -0.5 , while in Japan it is -0.15 , and in Spain it is -0.85 .

We test the stability of the Okun equation in the Baltics. We estimate the above equation for the three Baltic countries. We first estimate the equation for the entire sample period, and then perform 20-quarter rolling regressions. The estimation uses quarterly data and simple ordinary least squares, where $U^{*}$ and $Y^{*}$ were obtained using an HP filter with $\lambda=1600$. The sample period varies by country but basically covers the late 1990s through 2013Q3.

\begin{tabular}{|c|c|c|}
\hline & Beta & Adj. $R^{2}$ \\
\hline Anglo-Saxon & -0.42 & \\
\hline Australia & $-0.536^{\star * *}$ & 0.80 \\
\hline Canada & $-0.432^{\star \star *}$ & 0.81 \\
\hline Ireland & $-0.406^{\star * *}$ & 0.77 \\
\hline New Zealand & $-0.341^{\star * *}$ & 0.59 \\
\hline UK & $-0.343^{* * *}$ & 0.60 \\
\hline US & $-0.454^{\star * *}$ & 0.82 \\
\hline Nordics & -0.44 & \\
\hline Denmark & $-0.434^{\star \star \star}$ & 0.72 \\
\hline Finland & $-0.504^{\star \star *}$ & 0.77 \\
\hline Norway & $-0.294^{\star * \star}$ & 0.62 \\
\hline Sweden & $-0.524^{\star * *}$ & 0.62 \\
\hline DEU/NLD & -0.44 & \\
\hline Germany & $-0.367^{\star \star \star}$ & 0.51 \\
\hline Netherlands & $-0.511^{* * *}$ & 0.62 \\
\hline
\end{tabular}

\section{Estimates of Okun's beta for the Baltics are relatively high and relatively stable over time, featuring a slight downward trend.}

- The estimation over the entire sample period yields a value of Okun's beta of 0.42 on average, with Okun's beta slightly higher for Lithuania (0.49) than for Estonia (0.41) or Latvia (0.41). The fit of the model is good, as measured by a high adjusted R2 value. Broadly similar results are found when estimating the Okun's relationship in the specification in first-differences. In both specifications, the level of Okun's beta is similar to the average found in Ball et al. (2013) for Anglo-Saxon or Nordic countries, and is consistent with the relatively flexible labor market institutions that the Baltics share with these comparator country groups.

Table. Okun's Beta $1 /$

\begin{tabular}{lrrrr}
\hline & Beta & St. Error & P-value & Adj. $\mathrm{R}^{2}$ \\
\hline Estonia & -0.41 & 0.03 & 0.00 & 0.71 \\
Latvia & -0.41 & 0.02 & 0.00 & 0.84 \\
Lithuania & -0.49 & 0.04 & 0.00 & 0.73 \\
\hline
\end{tabular}

1/ Specification in levels.
Table. Okun's Beta 1/

\begin{tabular}{lrrrr}
\hline & Beta & St. Error & P-value & Adj. R $^{2}$ \\
\hline Estonia & -0.34 & 0.04 & 0.00 & 0.54 \\
Latvia & -0.39 & 0.03 & 0.00 & 0.71 \\
Lithuania & -0.43 & 0.04 & 0.00 & 0.66 \\
\hline
\end{tabular}

1/ Specification in differences. 
- The results of the rolling regressions indicate that Okun's beta has been on a gradual downward trend. However, this seems to be a feature that had set in well before the crisis, especially taking into account that estimates of Okun's beta are derived from the 20 quarters preceding the crisis. A simple regression of Okun's beta on a time trend shows that this is significant for Estonia and Latvia, but not for Lithuania. To test whether the slope of this trend has changed since the crisis, we interact this time trend with a postcrisis dummy that takes the value one for 2008Q1-2013Q3. This interaction term is not statistically significant in the case of Estonia or Latvia. For the case of Lithuania, we find a small but positive and significant value for the time dummy coefficient, implying that Okun's beta has decreased slightly in absolute value in the post-crisis period, even if a longer-term trend was not found to be significant.

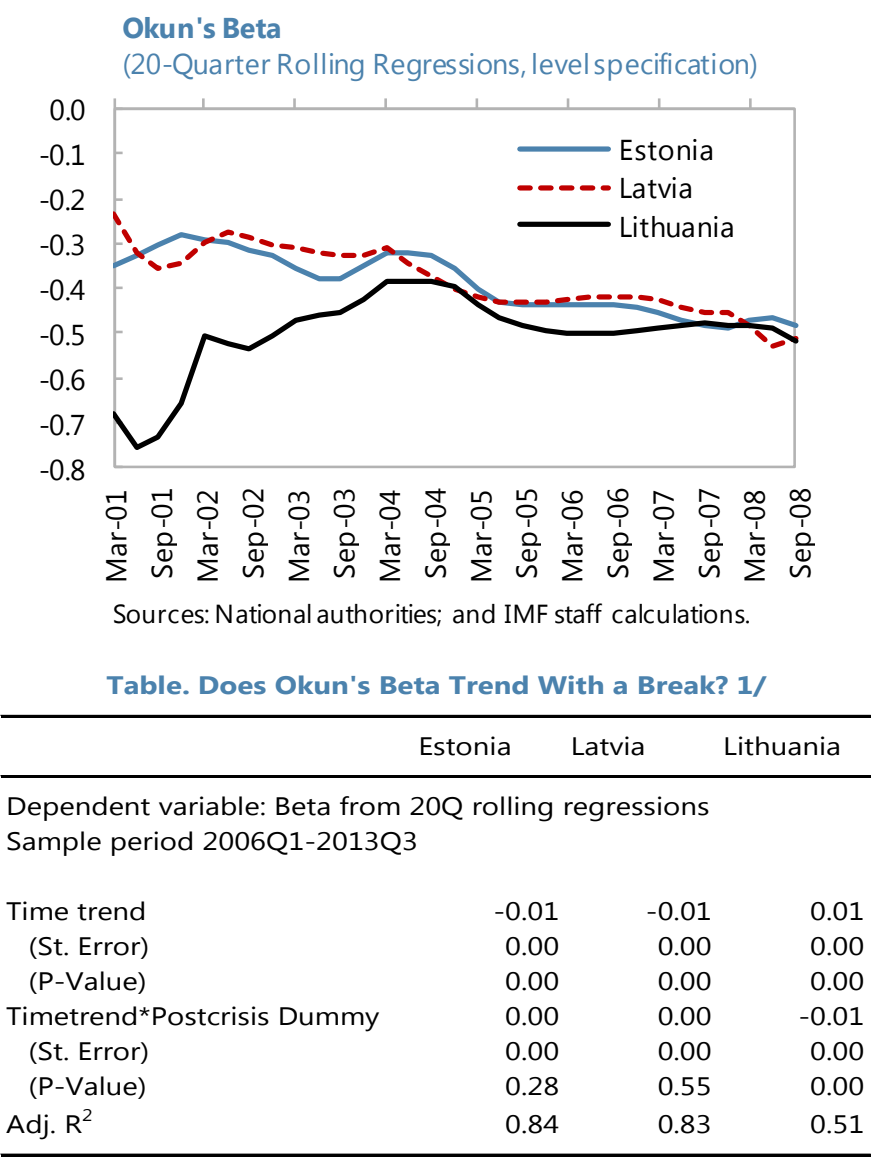

1/ Specification in levels from $20 \mathrm{Q}$ rolling regressions. Postcrisis dummy equals 1 for beta's estimated with a sample that includes at least 12 (out of 20) quarters in the post-crisis period (2008Q1 and after).

In summary, we find that the Okun's beta for the Baltics is relatively high, and while trending down, there is no strong indication of a break since the $2008 / 09$ crisis. The absolute value of Okun's beta is relatively high, and comparable to levels found for the Anglo-Saxon and Nordic countries. A higher beta is typically associated with a higher degree of labor market flexibility, and in this respect our finding on the size of beta suggests a 
relatively high degree of labor market flexibility also exists in the Baltics. We also find that the Okun's beta, while generally trending down over time, does not feature a break since the $2008 / 09$ crisis. This relative stability implies that the responsiveness of unemployment to output variations has not changed since the 2008/09 crisis. This is consistent with our finding that there is no evidence of a change in structural unemployment since the crisis.

\section{What Explains The High LeVEl OF STRUCTURAL UNEMPloyMent IN THE BALTICS?}

\section{This section examines possible explanations for high and persistent structural} unemployment in the Baltics. Because the literature typically relates structural rigidities in the labor market to high structural unemployment, we first explore this traditional hypothesis by looking at labor market characteristics, especially indicators of micro-flexibility of labor markets and the levels of tax wedge on labor. We then explore some non-traditional factors that may further help explain high levels of structural unemployment in the Baltics.

\section{A. Traditional Factors_Labor Market Characteristics}

\section{The Baltics score favorably on traditional indicators of labor market flexibility, implying these do not appear to explain high structural unemployment. Minimum wages do not appear excessive: expressed as a share of the mean wage, they are below or close to the OECD average. Unemployment benefits are much less generous than in OECD countries on average, providing strong monetary incentives for the unemployed to seek work. Employment protection is also on par with the OECD average.}

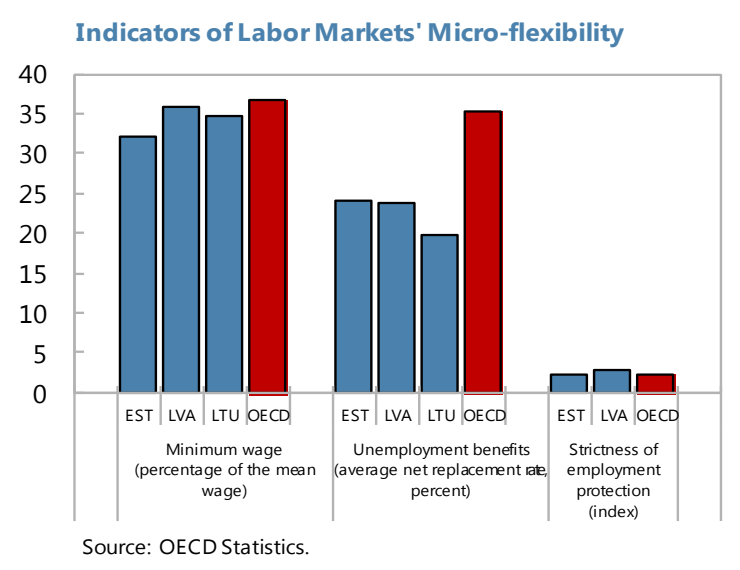

\section{Yet, labor tax wedges are high in the Baltics largely because of high social security} contribution rates. The tax wedge is measured here as the difference between labor costs to the employer and the net take-home pay of the employee. Economic theory suggests that high tax rates on labor income depress labor supply, employment, and expand the shadow economy. On the supply side, higher labor taxes depress labor supply and workers' effort by driving a wedge between marginal productivity and the reward for work. On the demand side, to the extent that wage earners succeed in shifting the tax burden onto employers, higher labor taxes raise labor costs which have adverse effects on employment. A high tax burden on labor creates an incentive to resort to the shadow economy that would result in lower tax revenue. 

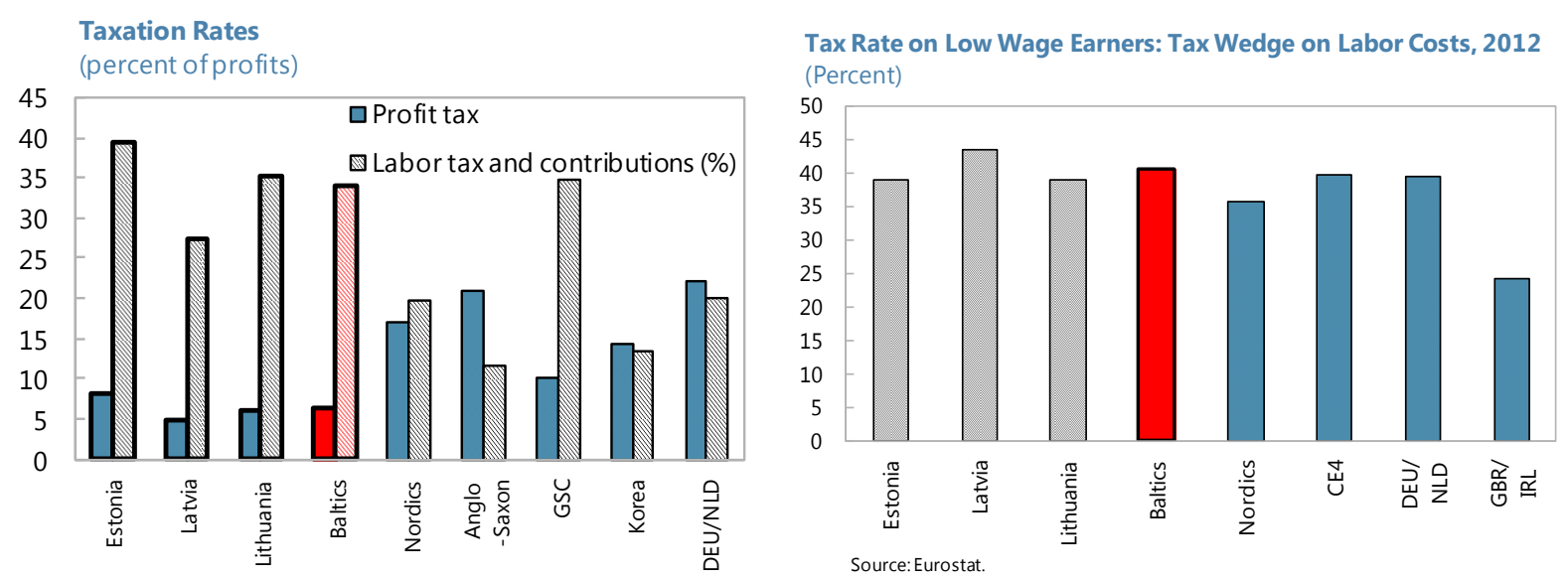

Source: World Bank Doing Business.

Recent econometric works find a strong and significant impact of labor taxation on the level of structural unemployment. Using cross-country data, the main finding of these studies is that the tax wedge is one of the main determinants of the level of structural unemployment.

Table. Recent Cross-country Studies on the Determinants of Structural Unemployment

\begin{tabular}{lcccc}
\hline Studies & Coefficient of tax wedge & Sample & Period & Technique \\
\hline & & & & \\
Gianella et al. (2008) & {$[0.34-0.36]$} & OECD 19 & $1978-2002$ & Panel GMM \\
Orlandi (2012) & 0.29 & EU 13 & $1985-2009$ & Panel fixed effects \\
European Commission (2013) & {$[0.173-0.223]$} & EU 15 & $1985-2008$ & Panel fixed effects \\
\hline
\end{tabular}

The sensitivity of structural unemployment with respect to the tax wedge is found to be large, significant, and relatively stable across these studies. The point estimate associated with the tax wedge variable ranges from 0.17 to 0.36 , depending on the studies. These results suggest that a reform of labor taxation in the Baltics which reduces the tax wedge by, for example, 10 percentage points would lead to a reduction in structural unemployment by 2 to 4 percentage points, all else equal.

We also confirm the role of the tax wedge in structural unemployment by setting up an event study. We have identified nine episodes of large declines in structural unemployment (a decline of at least 2.5 percentage points) based on the European Commission's time series estimates for structural unemployment (see Table and Figure below) in EU countries. We correlate these episodes with estimates of the tax wedge ratios (for the unskilled workers). In nearly all episodes identified, declines in structural unemployment are associated with significant reductions in the tax wedge. Latvia and Lithuania stand out as interesting special cases: In the two Baltics, recent large changes in the structural unemployment rate are not as large as those in other countries. Interestingly, the tax wedge did not significantly decline in these countries. 
Table. Historically Large Declines in Structural Unemployment

\begin{tabular}{lccc}
\hline Country & Period & $\begin{array}{c}\text { Reduction in tax } \\
\text { wedge }\end{array}$ & $\begin{array}{c}\text { Reduction in structural } \\
\text { unemployment }\end{array}$ \\
\hline & & & \\
Bulgaria & $2001-08$ & 8.5 & 8.3 \\
Finland & $1996-2008$ & 6.7 & 5.4 \\
Germany & $2005-13$ & 2.3 & 3.6 \\
Ireland & $1996-2001$ & 10 & 6.1 \\
Italy & $1996-2007$ & 5.5 & 2.5 \\
Poland & $2002-08$ & 3.4 & 5.9 \\
Slovakia & $2001-08$ & 5.2 & 3.7 \\
Spain & $1996-2007$ & -1.3 & 4.5 \\
\hline
\end{tabular}

Sources: Eurostat; AMECO database; and IMF staff estimates.

\section{We find a strong and positive correlation between large declines in structural} unemployment and corresponding changes to the tax wedge. The correlation coefficient from a simple univariate OLS regression is 0.4 with an $\mathrm{R}^{2}$ of 0.3 , suggesting that reductions in the tax wedge explain about 30 percent of the variation in structural unemployment. In summary, we find that reductions in the tax wedge are associated with declines in structural unemployment in both cross-country and event studies.

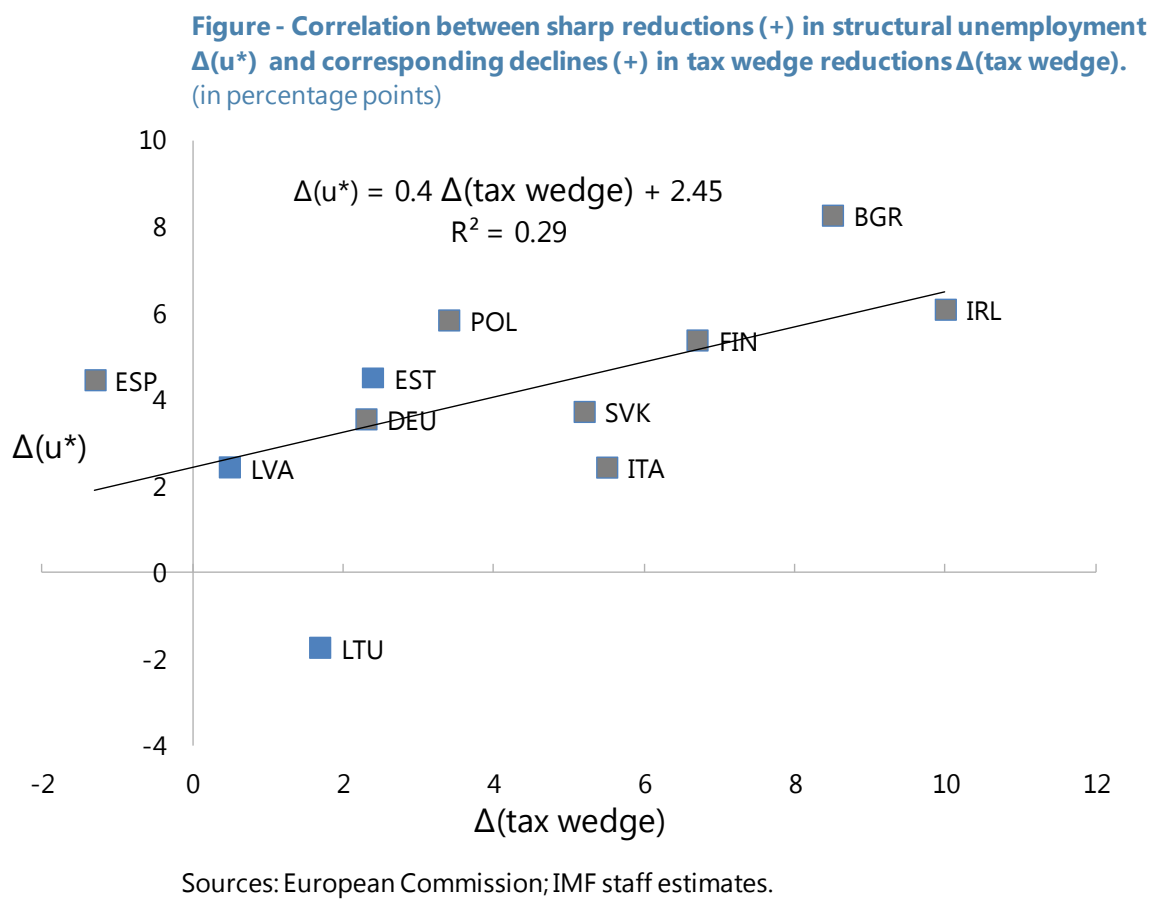




\section{High tax wedges, in combination with benefit changes, may also lead to high}

unemployment and inactivity traps. High taxes on labor, when combined with the loss of certain social and/or unemployment benefits upon finding employment decrease the net financial gain of taking up employment. This reduces the incentive for participating in the labor market, especially for lower-wage earners. This leads to unemployment and inactivity traps in the Baltics that are generally higher than those in the CE4, Anglo-Saxon, or other emerging market OECD countries.
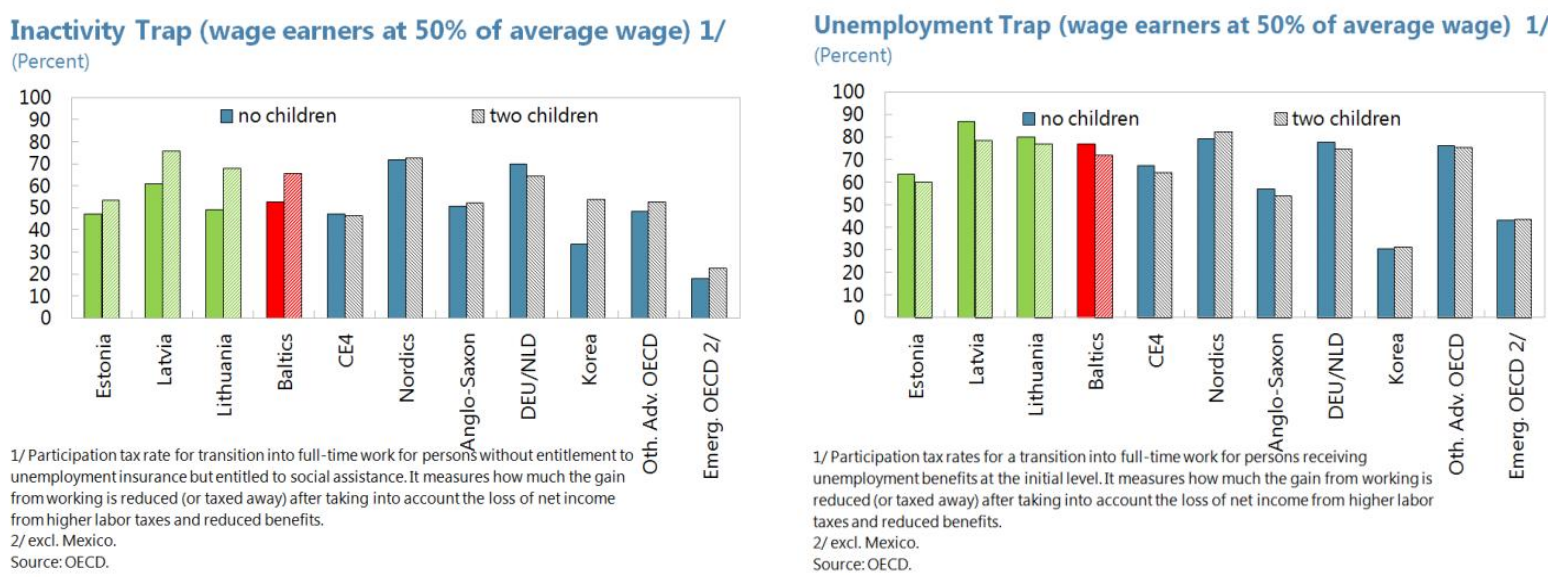

\section{B. Non-Traditional Factors}

\section{Are Skill Mismatches a Factor?}

Skill mismatches appear important amid mixed education outcomes. The Baltics score close to OECD averages on PISA tests given to secondary school students, indicating that quality of current education is broadly satisfactory. ${ }^{5}$ Tertiary enrollment rates are also in line with OECD averages (albeit male tertiary enrollment is low). Still, mismatches exist both in terms of the degree of educational attainment needed within a profession/sector and in terms of training in the right profession or sector. All three Baltics score worse than the average skill field mismatch. Skill mismatches and educational attainment also interplay with

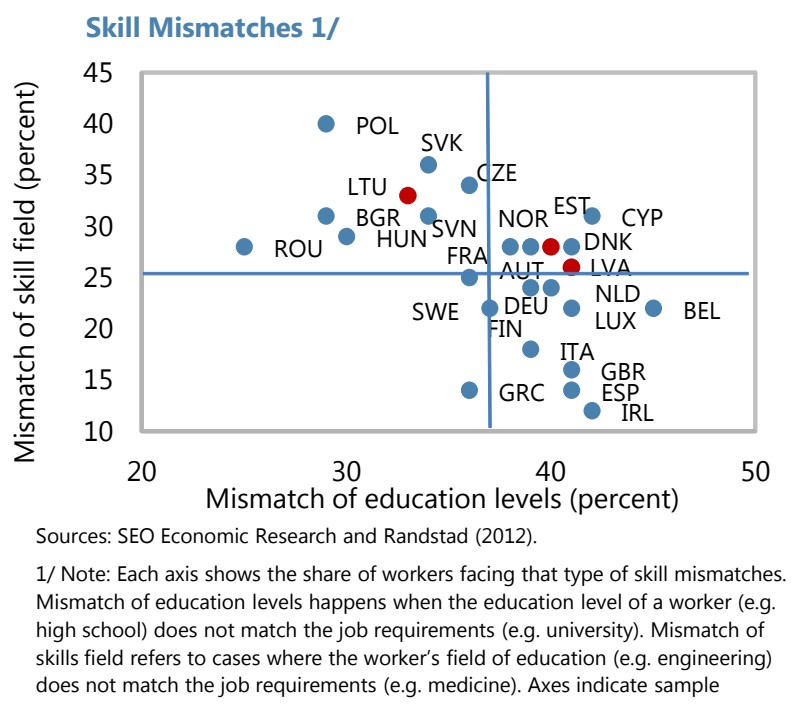

${ }^{5}$ There is variation among the Baltics with Lithuania lagging and Estonia outperforming the OECD average. 
regional divides. For example in the case of Lithuania, rural unemployment - which is much above urban unemployment - consists mostly of people with below-tertiary education.

Table: PISA Scores

\begin{tabular}{lrrrrr}
\hline & Estonia & Latvia & Lithuania & Baltic (ave.) & OECD (ave.) \\
Math & 521 & 491 & 479 & 497 & 494 \\
$\quad$ of which: & & & & & \\
$\quad$ Low performers 1/ & 10.5 & 19.9 & 26.0 & 18.8 & 23.0 \\
$\quad$ High performers 2/ & 14.6 & 8.0 & 8.1 & 10.2 & 12.6 \\
Reading & 516 & 489 & 477 & 494 & 496 \\
Science & 541 & 502 & 496 & 513 & 501 \\
$\quad$ of which: & & & & & \\
$\quad$ Low performers 1/ & 5.0 & 12.4 & 16.1 & 11.2 & 17.8 \\
$\quad$ High performers 2/ & 12.8 & 4.4 & 5.1 & 7.4 & 8.4 \\
$\quad$ Girls & 543 & 510 & 503 & 519 & 500 \\
\hline
\end{tabular}

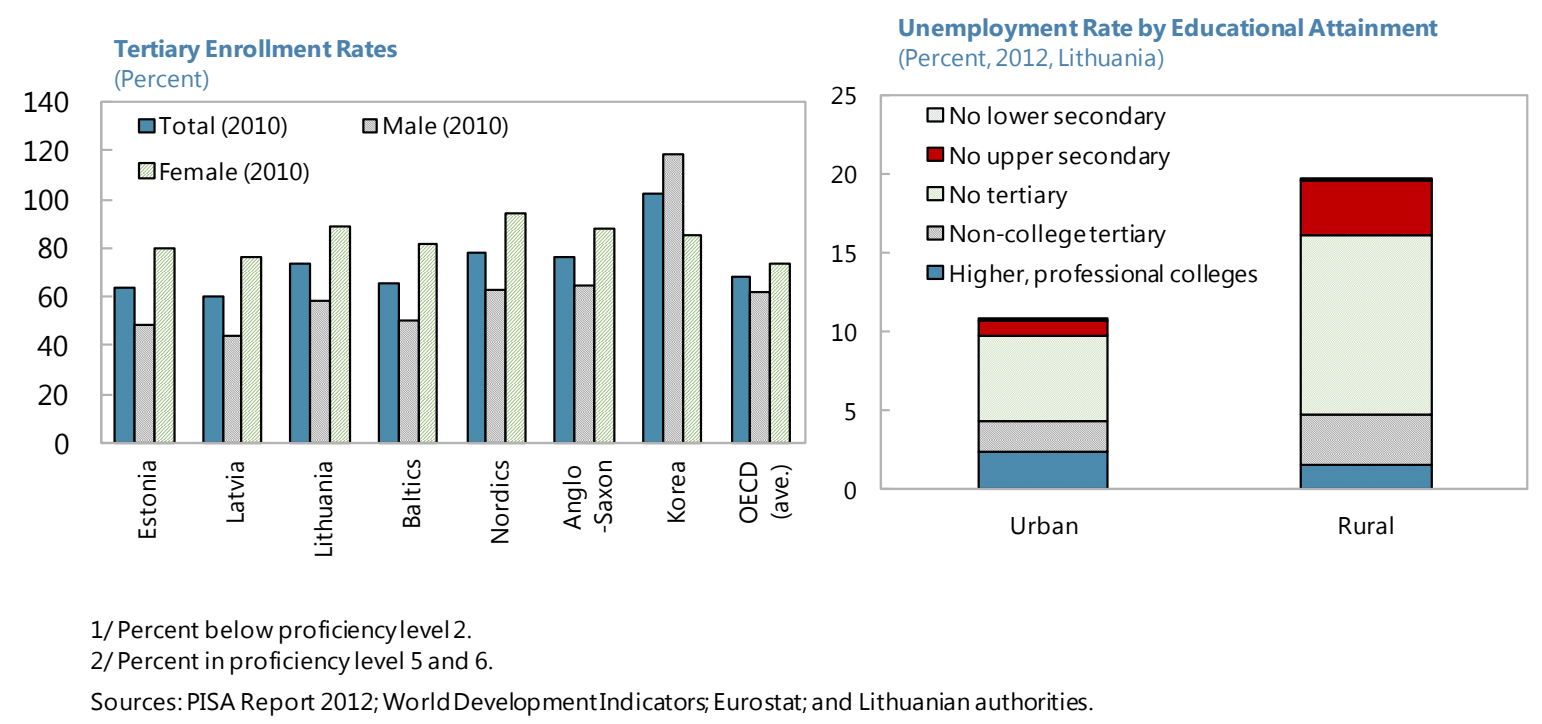

Training and active labor market policies to address mismatches are not widespread (Figure 3). Spending on active labor market policies (ALMPs) amounted to 0.5 percent of GDP in the Baltics, compared with over 2 percent in the Nordics; unlike Ireland and Iceland where ALMP spending was ramped up to significant levels since the 2008/09 crisis (Box 1), ALMP spending in the Baltics did not increase dramatically or the increases were from a small base (e.g. in the case in Estonia). Only 0.1 percent of GDP was spent on ALMP training in the Baltics-less than half that in the Nordics. Moreover, "passive" labor market support programs, including out-of-work income support and in the case of Latvia and Lithuania also early retirement, account for a very significant share of total ALMP spending in the Baltics. Low spending is not the result of high efficiency of ALMPs in the Baltics, but rather reflects very low participation in these programs. Longer-term averages of unemployment (especially for youth) seem to show a negative correlation with spending on ALMPs, indicating their potential in addressing skill mismatches. 


\section{Box 1. Iceland: Active Labor Market Policies During the Crisis}

During the 2008/09 crisis, Iceland implemented a number of ALMPs. With unemployment rising sharply following Iceland' banking and economic crisis, a number of measures were introduced to address high and rising unemployment. Measures initially focused on expanding registration for unemployment benefits and educating the public about available options. Gradually, other initiatives for active job seekers were introduced, including job retraining, subsidized hiring for trial periods, study programs, subsidized hiring, and volunteer work, opening secondary education to anyone under age 25 , programs that emphasized work-related education, and greater cooperation between social partners and the education system.

Iceland's experience demonstrates that ALMPs can be successful, even if they addressed mostly cyclical unemployment problems at the time. The wide scope of ALMPs and their gradually changing role over the course of the crisis helped to increase the number of participants in the programs. And while success rates vary, programs providing on-the-job training/apprenticeships or employment in specific projects seem to have increased chances of participants "de-listing" from the unemployment rolls. Available information suggests that about half of unemployed youth found jobs after participating in the programs.

Source: IMF (2011) 
Figure 3. Baltic Countries: Active Labor Market Policies and Labor Market Supports

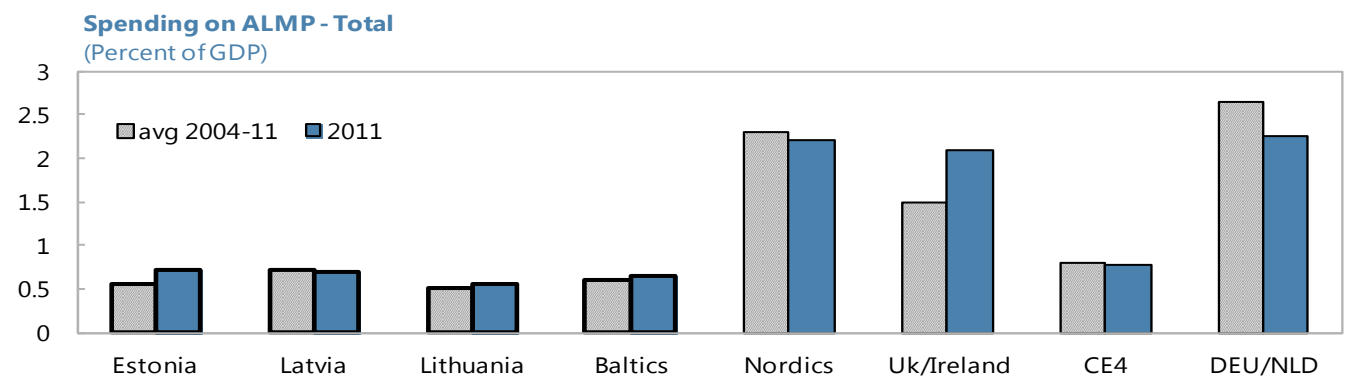

Spending on ALMP - Training

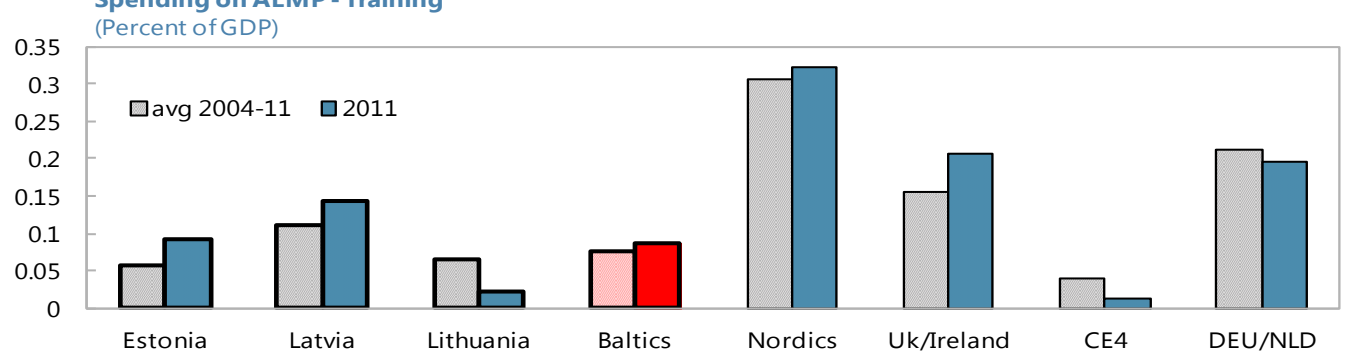

Participation in ALMP

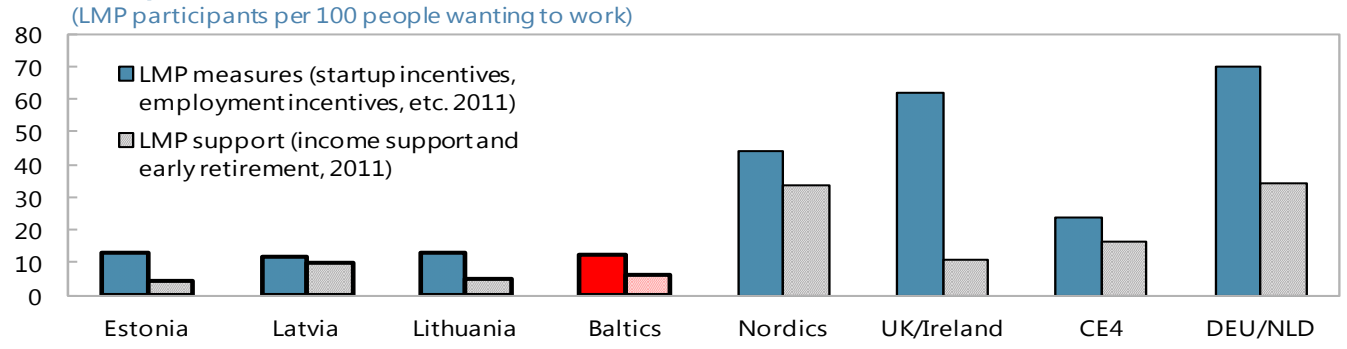

Participation in ALMP - Training, 2011

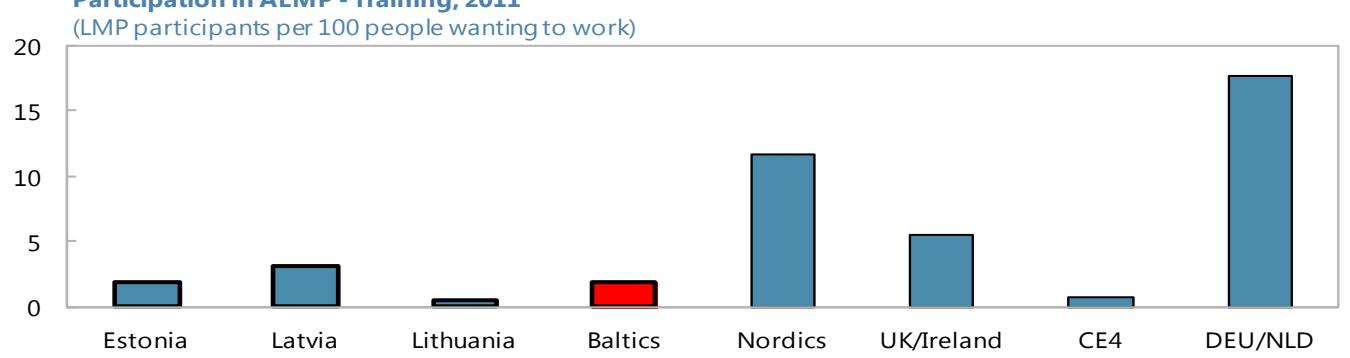

Source: Eurostat. 


\section{What Role Does Migration Play?}

In all three Baltic countries, the urban population has increased relative to the rural one, pointing to significant internal migration. In the case of Lithuania, where rural unemployment rates exceed those in urban areas, it is possible that the better skilled have migrated out of rural areas (leaving the rural population with a lower skill mix), but migration out of rural areas has not seemed to have exacerbated rural unemployment since the crisis. However, in the case of Estonia, rural unemployment rates are below those in urban areas, even if internal migration

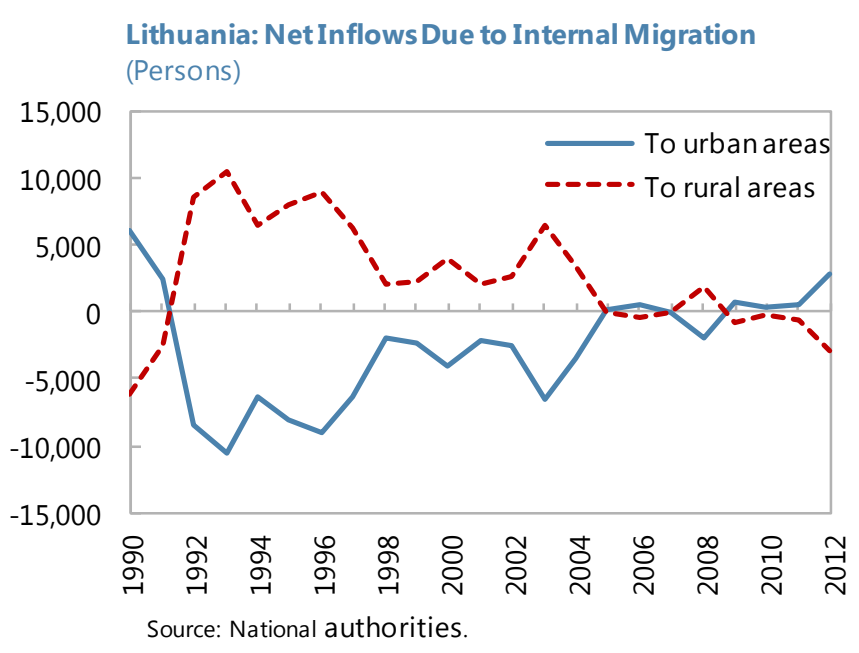
also leads to net inflows into urban areas.

The Baltic countries have also faced substantial emigration before and since the crisis. Migrants have been predominantly the young, with popular destinations being the UK and Ireland (for Latvia and Lithuania) and Finland (for Estonia). Much like internal migration to urban areas, migrants leaving the Baltics may have been those with the best skills and best equipped for finding jobs abroad. To quantitatively assess the role played by changes in population (from international migration), we perform a canonical decomposition of the unemployment rate. We follow and extend the methodology discussed in OECD (2012) by taking into account changes in total population. More formally, the decomposition of the unemployment rate can be approximated by the following formula:

$$
\begin{gathered}
\Delta\left(\frac{U}{L F}\right) \approx-\Delta \ln \left(1-\frac{U}{L F}\right)=-\Delta \ln \left(\frac{E}{L F}\right) \\
=-\Delta \ln \left(\frac{Y}{N} \cdot \frac{E H W}{Y} \cdot \frac{E H}{E H W} \cdot \frac{E}{E H} \cdot \frac{1}{L F} \cdot \frac{N}{1}\right)=\Delta \ln \left(\frac{1}{\left(\frac{Y}{N}\right)} \cdot \frac{Y}{E H W} \cdot \frac{E H W}{E H} \cdot \frac{E H}{E} \cdot \frac{L F}{1} \cdot \frac{1}{N}\right),
\end{gathered}
$$

where $U$ refers to the number of persons unemployed, $L F$ to the number of participants in the labor force, $E$ to the number of persons employed, $H$ to average hours worked, $W$ to the hourly wage, $Y$ to the real GDP and, $N$ to the total population. From equation [1], changes to the unemployment rate arise from: $i$ ) the change in the real GDP per capita; $i i)$ the change in the quality-adjusted labor productivity (simply measured as the ratio of output to the wage bill); iii) the change in average hourly wages; $i v$ ) the change in average hours worked; $v$ ) the change in labor force participation; and vi) the change in total population. Annual data spanning from 2008 to 2012 are used for each of the three countries of the region. 
The decomposition confirms the prominent role played by real wages, hours worked, and real income in explaining the large movements in the unemployment rate. ${ }^{6}$ First, unemployment accelerations were uniformly associated with sharp declines in per capita GDP, compressed real wages and to some extent with the drop in the number of hours worked (in Latvia and Estonia) suggesting that labor costs significantly adjusted downward during the crisis. The other factors (population and labor force participation) played a very limited role. Second, the deceleration in the unemployment rates across countries was associated with recoveries in the per capita GDP and surprisingly by improvements in the quality-adjusted labor productivity (especially in Latvia and Lithuania). Wages and the number of hours worked were almost flat. However, a decomposition of unemployment demonstrates that population change has contributed only to a very small fraction in the total change in unemployment during the crisis.

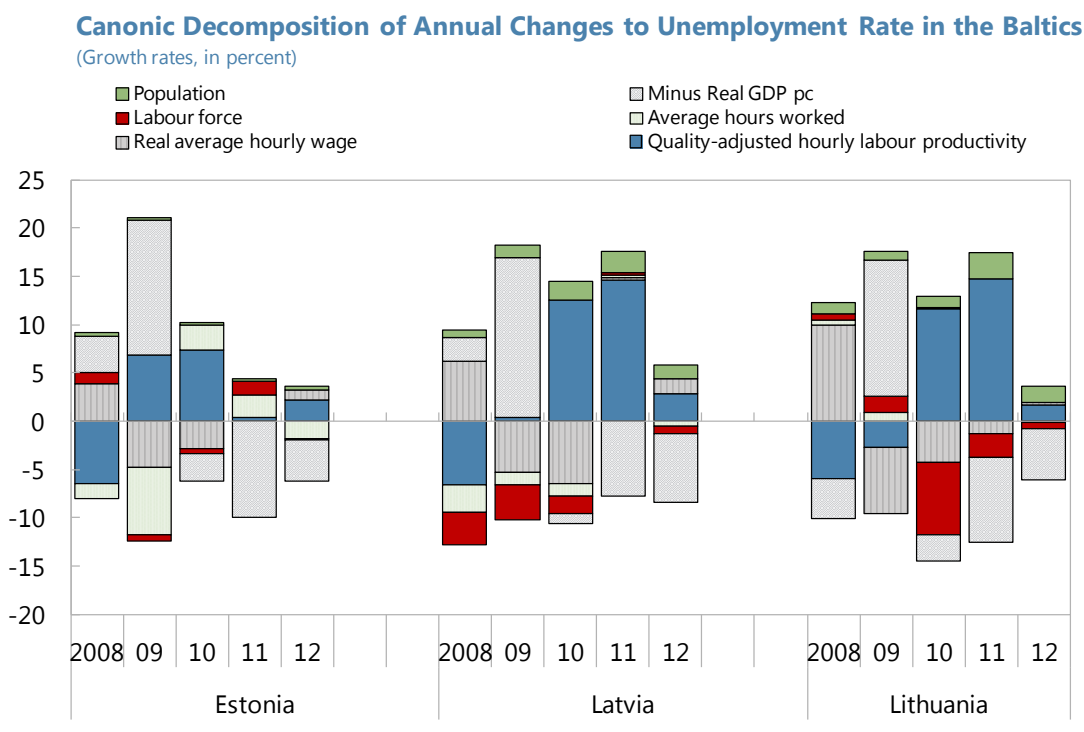

Sources: IMF staff estimates

\section{Conclusions ANd Policy Recommendations}

This paper has found that high unemployment in the Baltics mainly reflects structural factors. Our analysis suggests that structural unemployment is in double digits and close to actual levels but also that it has not significantly worsened following the 2008/09 crisis.

The underlying reasons for high structural unemployment are diverse. They seem to relate to high taxation of labor, residual shortcomings in the education system that cause skill mismatches, limited policy intervention to address skill mismatches through ALMPs, and

\footnotetext{
${ }^{6}$ The decomposition should give a close to perfect approximation when the unemployment rate is relatively small. In the case of the Baltics, the unemployment rate is relatively high (two-digits) implying that the components of the first-order Taylor decomposition may not necessarily sum up to the observed changes in the jobless rate for some years.
} 
specific rigidities in rural areas that prevent growth to translate into more jobs (at least for the case of Lithuania).

\section{While some of these reasons are better understood than others, a number of policy recommendations emerge:}

- Reconsider labor taxation. Cross-country experience suggests that reductions in the tax wedge can be associated with significant declines in structural unemployment. At the same time, revenue to GDP ratios in the Baltic countries are already low, suggesting that reductions in labor taxation need to be carefully considered and offset with other sources of revenue. Options include increasing taxation on capital and wealth, base broadening, and improvements in revenue administration. In all cases, changes to the tax system would need to be complemented with improvements in revenue administration to ensure that revenue shortfalls do not materialize. And adjustments in tax rates could be considered in a coordinated manner.

- Improve education outcomes. As small economies at the fringes of Europe, the Baltics may need to exceed educational outcomes in other countries in order to attract FDI and other investments. Estonia is already well on the way to achieve this, but there is scope to improve educational outcomes in Latvia and Lithuania. Specific policies could include better coordination between universities are employers to help reduce education and skill mismatches.

- Increase spending and participation in ALMPs. There is ample scope to utilize ALMPs to help reduce skill mismatches, especially among the unemployed. Given the Baltic countries tight links with their Nordics, and the Nordics effective use of ALMPs, a policy dialogue which seeks to draw lessons from the Nordic experience could help inform policy choices by the Baltic authorities. Available EU funds could support stronger ALMPs.

- Enhance the policy dialogue. Policy fora on tackling high unemployment could provide a venue for Baltic policymakers to draw on each other's experiences. These fora could be expanded to include their Nordic partners in areas where there is a long tradition of relative success, such as in education and training policies.

- Review incentives for high rural unemployment, in the case it exceeds urban unemployment by a significant margin. While a more thorough analysis may be needed, tax incentives for those engaged in agricultural activity, high informality in rural areas, and benefit incentives, may be behind the high number or rural unemployed. Policy to address these issues in turn and in tandem, combined with ALMPs could help reduce rural unemployment. To the extent regional mobility is a factor (along with the cost of living in urban areas), spending on regional infrastructure to connect urban and rural areas may be needed. 


\section{REFERENCES}

Ball, L., Leigh, D., and Loungani, P. 2013. Okun's Law: Fit at 50? IMF Working Papers 13/10, International Monetary Fund.

Bonthuis, B., Jarvis, V., and Vanhala, J. 2013. What's going on behind the euro area Beveridge curve(s)? Working Paper Series 1586, European Central Bank.

Elsby, M., Hobijn, B., and Şahin, A. 2013, Unemployment Dynamics in the OECD, The Review of Economics and Statistics, Vol. 95, No. 2, pp. 530-548.

Gianella, C., Koske, I., Rusticelli, E., Chatal, O., 2008. What Drives the NAIRU? Evidence from a Panel of OECD Countries. OECD Economics Department Working Paper No. 649. OECD Publishing.

Giuliano, P. and A. Spilimbergo, 2009. Growing up In a Recession: Beliefs and the Macro Economy, NBER Working Paper 15321.

Guichard, S., Rusticelli, E., 2011. Reassessing the NAIRUs after the Crisis. OECD Economics Department Working Papers No. 918. OECD Publishing.

IMF, 2010. World Economic Outlook April 2010: Rebalancing Growth, The International Monetary Fund, Washington, D. C., USA.

IMF, 2011. Iceland: Fifth Review Under the Stand-By Arrangement, and Request for Modification of Performance Criteria and Rephasing of Access-Staff Report, Country Report No. 11/125, The International Monetary Fund, Washington, D. C., USA.

IMF, 2013. World Economic Outlook April 2013: Hope, Realities, Risks, The International Monetary Fund, Washington, D. C., USA.

Laubach, T., 2001. Measuring The NAIRU: Evidence From Seven Economies. Rev. Econ. Stat. 83, 218-231.

OECD, 2012, OECD Employment Outlook 2012, OECD Publishing. 